\title{
Optimal Renewable Generation Mix of Hydro, Wind and Photovoltaic for Integration into the Portuguese Power System
}

\author{
Jorge Sousa, MIEEE \\ ISEL - Lisbon Engineering Superior Institute \\ INESC-ID \\ Lisbon, Portugal \\ jsousa@deea.isel.ipl.pt
}

\author{
Ana Martins \\ ISEL - Lisbon Engineering Superior Institute \\ BRU-UNIDE \\ Lisbon, Portugal \\ anamartins@deea.isel.ipl.pt
}

\begin{abstract}
In spite of the advantages of renewable energy sources (RES), their variability and uncertainty raises important issues in power systems operation, such as the need to balance demand with a highly variable and uncertain power generation. In this context, is of utmost importance the choice of the optimal renewable generation mix to be integrated in the power system in order to accomplish the established renewable energy targets with the lowest technical impacts. With this aim, this paper presents a methodology that supports decision making on the renewable energy policy by deriving the optimal renewable generation mix from different available technologies - hydro, wind and photovoltaic - that integrates a given amount of electricity from renewable sources, taking into account the variability of the renewable generation mix and the target share of renewable generation. This methodology is applied to a case study of one month using renewable generation data of the Portuguese power system.
\end{abstract}

Index Terms--Renewable generation mix, Large-scale integration, Variability, Power systems.

\section{INTRODUCTION}

In order to reduce the greenhouse gas emissions and the dependence on energy imports, renewable energies sources (RES) have been promoted worldwide. At the European level the Directive 2009/28/EC [1] endorses mandatory national targets for RES, for 2020 , consistent with a $20 \%$ share in the energy consumption in the Community and a minimum $10 \%$ share in the transportation sector in all Member States. To achieve the established targets, huge investments have been made in renewable capacity in the Portuguese power system, especially in what concerns wind power. As a result, Portugal became in 2010 the second country in the world with the highest share of wind power in the electricity generation [2].

In spite of the advantages of the RES integration in the power systems, their variability and uncertainty raises important issues related to the power system operation [3]. Kabooris and Kanellos [4] focused on the load following

This work was supported by national funds through FCT - Fundação para a Ciência e a Tecnologia, under project PEst-OE/EEI/UI4064/2011 and project MAN-REM: Multi-agent Negotiation and Risk Management in Electricity Markets (FCOMP-01-0124-FEDER-020397). frequency control as a major technical problem in systems with significant wind power generation. The adequate integration of high shares of renewable sources requires a combination of measures such as system flexibility, storage, wind curtailment, wind ramp-rate mitigation, demand response and the effective use of the interconnections. The analysis of the integration of large scale highly variable renewable sources has been made for several countries [5], especially for those with high shares of wind power, such as Denmark [6], Netherlands [7], Portugal [8]-[10] and Nordic countries [11].

On the other hand, it is recognized that renewable power sources can contribute partially for the system security. In this regard, the capacity value of a power unit, namely a renewable power source, might be defined as the additional load that can be served at the same reliability level due to the inclusion of that power unit.

Concerning the impacts on the reserve requirements needed to cope with the variability and uncertainty of the renewable sources, Holttinen and Hirvonen [12] concluded that the reserve requirements of different loads and wind power interact and partly compensate each other. A scenario analysis of different combinations of wind, solar and wave was performed in [13] to compute the reserve requirements that results from the variability and uncertainty of the corresponding generation mix. This study concluded that a diversified renewable energy mix reduces the reserve requirements and mitigates the effects of the variability of the renewable sources. Also, in a large study for the Nordic countries, a detailed statistical analysis of hourly wind power generation was performed for Denmark, Sweden, Norway and Finland, in order to access the impact of large-scale regional aggregation of wind power [14].

The smoothing effect of integrating different sources has also been studied for other renewable sources, either individually or in combination. Examples are the analysis of wind power in Portugal [15], the photovoltaic (PV) systems in 
Germany [16], combinations of off-shore wind and waves in California [17], combinations of wind and waves in Ireland [18], combinations of wind and solar in Sweden [19] and in Europe [20]. The importance of taking into account the penetration of solar PV or ocean power, which mitigates the variability of individual technologies, is emphasized in [21].

In fact, diversified renewable generations mix results in a smoother generation profile with increased predictability and decreased probability of extremes values, which in turn, reduces the system reserves requirements. In this direction, Lund [22] computed optimal combinations of PV, onshore wind and wave power for the Danish system by minimizing the excess power generation using the EnergyPLAN model. It was concluded that the optimal mix corresponds to $50 \%$ of onshore wind power and the remaining 50\% are distributed between PV and wave. A multi-objective method was used in [23] to optimize the mix of the renewable generation in the Portuguese system. The global optimization problem put a $50 \%$ weight on the costs and a $50 \%$ weight on reliability issues which, in turn, accounts for the yearly and monthly variability and the contribution to the winter and summer peak load.

In line with a multi-objective approach, this paper presents a methodology to compute the optimal renewable generation mix to be integrated in a power system, taking into account a given target of renewable share and the variability of the residual demand, defined as total demand minus production from renewables, that is to be met by thermal generation technologies.

The presented methodology is applied to the Portuguese case study for a combination of hydro, wind and PV renewable generation sources for a period of one month with a 15-minute data.

\section{Methodology}

The integration of highly variable renewable generation sources in a power system presents challenges and difficulties regarding both short-term operational issues and long-term planning activities.

As operational issues are concerned, the system operator is responsible for balancing the power generation and the demand, which implies the need to cope with the variability of the renewable sources generation.

As for planning purposes, forecasting the backup capacity needed in periods with low renewable generation, and the storage capacity needed in periods with excess of renewable generation, presents a major challenge both for market players and for the system operator.

Therefore, decreasing the variability of the residual demand, keeping at the same time the renewable energy policy goals, is a valuable contribution for a large scale integration of renewable sources into the power systems.

For this purpose, using a multi-objective formulation, the proposed methodology incorporates the goals of the residual demand variability minimization and the renewable energy policy target accomplishment.

\section{A. The Model}

Let $D_{t}$ represents the electricity demand at time $t$ $(t=1, \ldots, T)$ and $R_{i t}$ the renewable generation from technology $i(i=1, \ldots, I)$ at time $t$, which is normalized by the maximum value observed in the considered period for each renewable technology.

The optimization problem to solve is presented in (1):

$$
\begin{aligned}
\min _{a_{i}} & \left\{\gamma_{1} \operatorname{VAR}\left(D_{t}-\sum_{i=1}^{I} a_{i} R_{i t}\right)+\right. \\
& \left.+\gamma_{2}\left(\lambda E\left(D_{t}\right)-E\left(\sum_{i=1}^{I} a_{i} R_{i t}\right)\right)^{2}\right\},
\end{aligned}
$$

where $a_{i}$ are the decision variables which represent the installed capacity of each renewable generation technology $i$. The total renewable generation, at time $t$, is therefore obtained by $\sum_{i=1}^{I} a_{i} R_{i t}$.

The objective function in problem (1) presents two components weighted by the parameters $\gamma_{1}$ and $\gamma_{2}$, with

$$
\gamma_{1}+\gamma_{2}=1
$$

The first component, weighted by $\gamma_{1}$, represents the variance of the residual demand, given by the difference between the demand and the total renewable generation. The goal is to minimize the variability of the gap between the electricity demand and the renewable production, which corresponds to the residual demand that is to be met by the thermal generation technologies.

The second component, weighted by $\gamma_{2}$, considers the squared deviations between a target share $\lambda$ of renewable generation in the demand. This way, a renewable share of $\lambda$ offsets this second component leading to a minimum value of 0 .

The maximum of the demand which is accounted by renewable sources, at time $t$, is represented by the parameter $\varepsilon$ and is considered in the model by the constraint:

$$
\sum_{i=1}^{I} a_{i} R_{i t} \leq \varepsilon D_{t}
$$

This constraint expresses the maximum share of renewable generation allowed to fulfill the demand. In particular $\varepsilon=1$ intends to represent the case in which the total renewable generation cannot exceed the electricity demand. This means that no renewable generation curtailment would occur under the circumstances that, within the input data of renewable generation, no curtailment occurred. 


\section{CASE SYUDY}

The described methodology was applied to a real case study of RES integration into the Portuguese power system, where three renewable sources were considered:

$$
\begin{aligned}
& H_{t} \quad: \text { hydro generation; } \\
& W_{t} \text { : wind generation; } \\
& P V_{t}: \text { photovoltaic generation. }
\end{aligned}
$$

The optimization problem is written, for this particular case, as follows:

$$
\begin{aligned}
& \min _{a_{i}}\left\{\gamma_{1} \operatorname{VAR}\left(D_{t}-\left(a_{1} H_{t}+a_{2} W_{t}+a_{3} P V_{t}\right)\right)+\right. \\
& \left.\gamma_{2}\left(\lambda E\left(D_{t}\right)-E\left(a_{1} H_{t}+a_{2} W_{t}+a_{3} P V_{t}\right)\right)^{2}\right\},
\end{aligned}
$$

Subject to the constraint:

$$
a_{1} H_{t}+a_{2} W_{t}+a_{3} P V_{t} \leq \varepsilon D_{t} .
$$

\section{A. Input data}

As input data it was considered the demand and renewable generation from hydro, wind and PV for one month (January 2011) with 15-minute time steps obtained from the Portuguese system operator [24]. This approach assumes that the renewable generation is an adequate proxy of the renewable resources converted into power through the corresponding technology. This assumption has the advantage of using easily available data and is adequate to illustrate the potential of the presented methodology. It has however the disadvantage of hide some potential renewable curtailment that might have occurred during the analyzed period.

Fig. 1 shows this input data for the renewable generation technologies (hydro, wind and PV) which accounted (on average), in this month, for $48 \%$ of the demand.

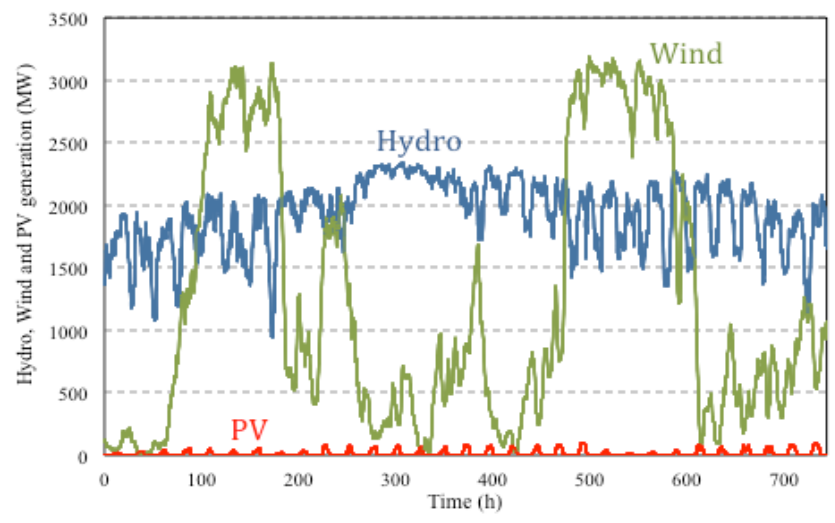

Figure 1. Hydro, wind and PV generation of the Portuguese power system in January 2011 for 15-minute time steps.
The correlation coefficients among demand, hydro, wind and PV generation are presented in Table I:

TABLE I. CORRELATION COEFFICIENTS AMONG DEMAND, HYDRO, WIND AND PV

\begin{tabular}{|l|c|c|c|}
\hline & Hydro & Wind & PV \\
\hline Demand & 0.506 & 0.099 & 0.275 \\
\hline Hydro & 1.000 & -0.235 & 0.238 \\
\hline Wind & -0.235 & 1.000 & -0.135 \\
\hline
\end{tabular}

It is observed that hydro generation has the highest correlation with demand, followed by PV generation. Moreover, wind generation is very weakly correlated with demand and is negatively correlated with hydro and PV.

\section{B. Results}

For the considered renewable generation and demand data, simulations were carried out using MATLAB, by applying the optimization methodology presented in section II for different scenarios. The constrained nonlinear minimization problem is solved using the active-set algorithm of the fmincon MATLAB function.

The base case scenario is obtained by setting $\gamma_{1}=\gamma_{2}=$ 0.5 , which corresponds to weighting equally the variability and the renewable share target. In this scenario, the renewable share target is kept equal to the real case, which is $48 \%(\lambda=$ 0.48 ) and the renewable generation is not allowed to exceed the electricity demand in each period $(\varepsilon=1)$.

The optimal renewable generation mix that fulfills the variability and the renewable target objectives is computed by solving the problem (4) and (5).

The results obtained correspond to the following installed capacity for each renewable technology:

$$
\begin{aligned}
& \mathrm{a}_{1}=3410.74 \mathrm{MW} \text { (hydro); } \\
& \mathrm{a}_{2}=640.21 \mathrm{MW}(\text { wind); } \\
& \mathrm{a}_{3}=988.07 \mathrm{MW}(\mathrm{PV}) .
\end{aligned}
$$

The power generated by each renewable technology is obtained by multiplying the above installed capacity and the utilization factor of each one. Therefore, the shares of capacities will be necessarily different from the power generation shares.

In Fig. 2 it can be seen the electricity demand and the total renewable generation for the real case and for the optimized base case scenario.

The upper graph presents the real data of electricity demand and renewable generation (hydro, wind and PV) and the lower graph depicts the optimization results with the achieved optimal renewable generation mix. 

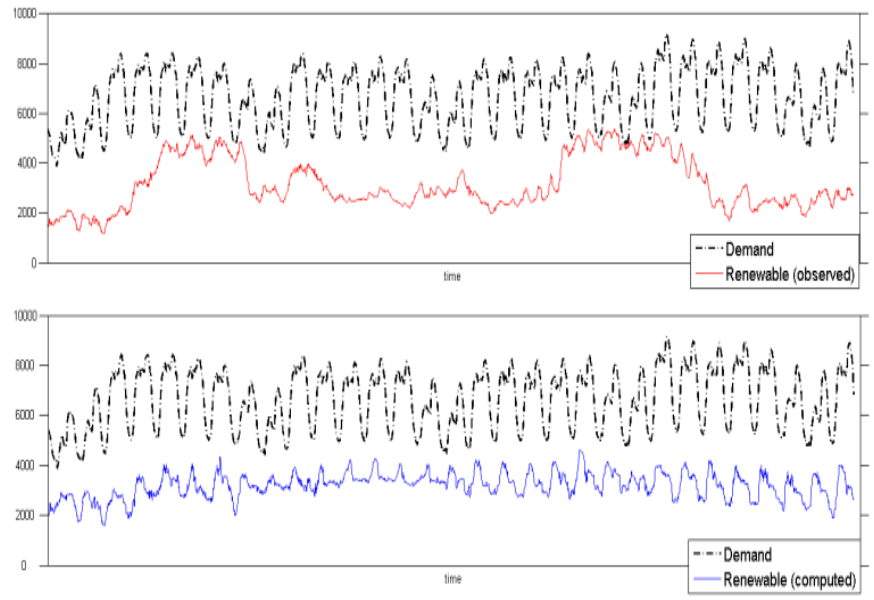

Figure 2. Demand and total renewable generation, in MW. Real case, in the upper graph, and optimized results, in the lower graph (with $\gamma_{1}=\gamma_{2}=0.5$,

$$
\varepsilon=1 \text { and } \lambda=0.48) \text {. }
$$

From Fig. 2 it is observed that the optimized renewable generation mix leads to a much more stable behavior of the residual demand than the real case.

In fact, the achieved results put in evidence a clear drop of $26.8 \%$ in the residual demand variability for the same renewable share of $48 \%$. This corresponds to a decrease of the residual demand standard deviation from $1406 \mathrm{MW}$ to $1030 \mathrm{MW}$.

Furthermore, the renewable generation mix improved its correlation with the demand in $137 \%$, with an increase of the correlation coefficient from 0.24 to 0.57 . This correlation coefficient of the optimized renewable generation mix is higher than the correlation of any of the individual technologies, namely of the hydro that presents the highest correlation with the demand (0.506). This is achieved by combining the hydro generation, which presents the higher correlation with the demand, with wind (that is negatively correlated with hydro) and PV, which increases the correlation of the global mix with the demand.

A major advantage of integrating an optimized renewable generation mix into the power system is the resulting residual demand that is fulfilled with conventional thermal power plants for a given renewable target.

In this regard, an optimized renewable generation mix requires a lower installed backup capacity and increases the capacity factor of the thermal power plants, which is a critical aspect for their economic viability.

To emphasize the result of the presented methodology applied to the Portuguese power system, Fig. 3 presents the residual demand duration curve for the real case and for the optimized renewable generation mix base case scenario.

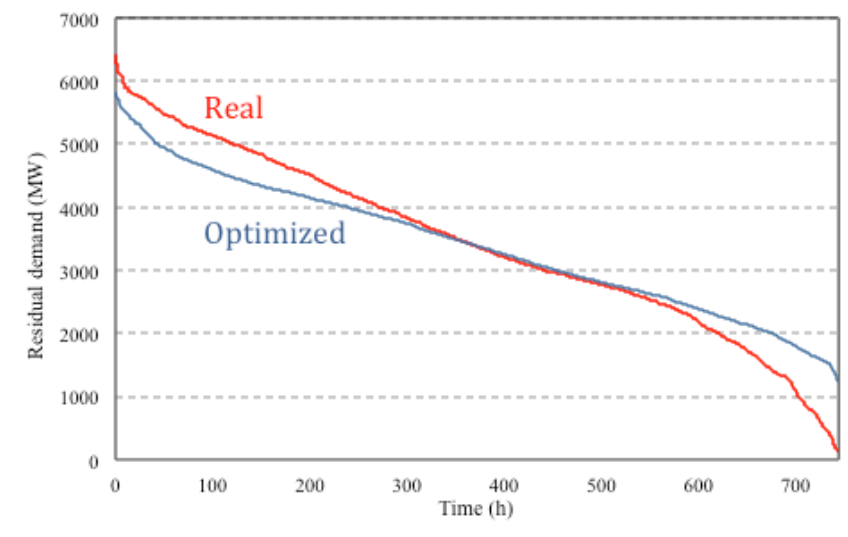

Figure 3. Residual demand duration curve for the real case and for the optimized base case scenario.

It is observed that the maximum thermal capacity need decreases from $6393 \mathrm{MW}$, in the real case, to $5810 \mathrm{MW}$, for the optimized renewable generation mix base case scenario.

Several scenarios were also considered for different balances between the goals of minimizing the residual demand variability and achieving a desired renewable share target in problem (4) constrained by (5). This is performed with different weights $\gamma_{1}$ and $\gamma_{2}$, taking into account equation (2) for the real renewable target $(\lambda=0.48)$ without curtailment $(\varepsilon=1)$.

The resulting generation share of each renewable source in the total renewable generation is presented in Fig. 4, for the real case and for three simulated scenarios: $\gamma_{2}=0\left(\gamma_{1}=1\right), \gamma_{2}=$ $0.5\left(\gamma_{1}=0.5\right)$ and $\gamma_{2}=1\left(\gamma_{1}=0\right)$.

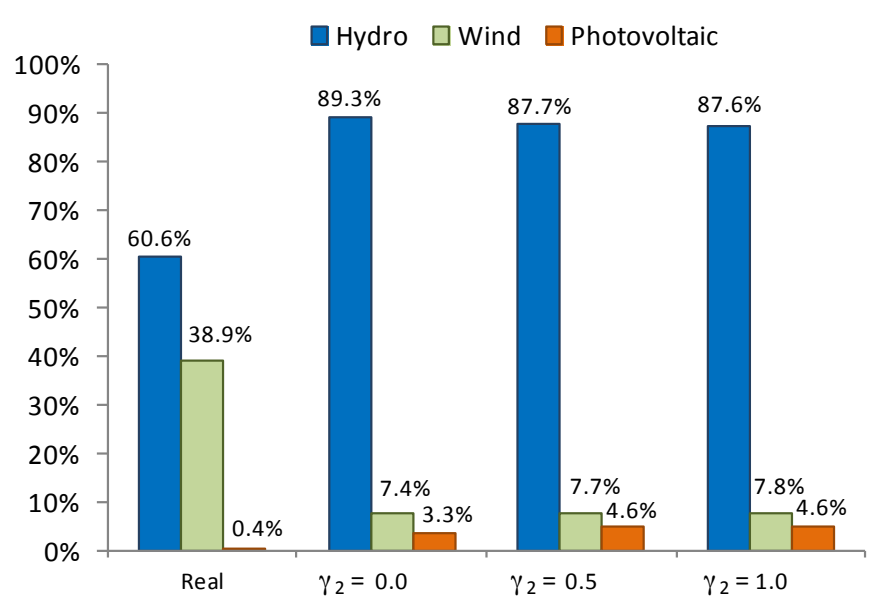

Figure 4. Share of hydro, wind and photovoltaic generation in the total renewable generation. Comparison between the real case and computed optimized results for $\gamma_{2}=0, \gamma_{2}=0.5$ and $\gamma_{2}=1 \quad(\varepsilon=1$ and $\lambda=0.48)$. 
When comparing with the real case (first case of Fig. 4) it is observed an increase in the generation share of the hydro and PV and a decrease of the wind contribution.

This result is explained mainly by the residual demand variability minimization component of the optimization problem, since hydro and PV generation are the renewable sources which are most correlated with the demand.

Wind generation has a much lower contribution in the optimal renewable generation mix (less than 8\%) when compared to the real case $(38.9 \%)$ not only because of its low correlation with demand but also due to its high variability.

This later factor limits the contribution of wind in achieving a given renewable target due to the risk of curtailment, which was not allowed in the simulated scenarios.

The influence of the limit to the maximum renewable generation that can be used to satisfy demand in each period in the optimal renewable generation mix is obtained for increasing values of the model parameter $\varepsilon$. These simulations were carried out taking into account only the minimization of the variability of the residual demand $\left(\gamma_{1}=1\right)$. In this case the renewable target does not influence the results once $\gamma_{2}=0$.

The results are shown in Table II, which presents the considered limit for the instantaneous renewable generation $(\varepsilon)$, the optimization results for each renewable technology capacity $\left(a_{1}, a_{2}\right.$ and $\left.a_{3}\right)$, the residual demand standard deviation $\left(\mathrm{S}_{\mathrm{Y}}\right)$, the total renewable quota $\left(\mathrm{Q}_{\mathrm{REN}}\right)$, and the share of each renewable source in the total renewable generation $\left(\mathrm{Q}_{\mathrm{H}}, \mathrm{Q}_{\mathrm{W}}\right.$, QPV).

TABLE II. IMPACT OF THE LIMIT TO THE MAXIMUM RENEWABLE GENERATION ON THE OPTIMAL RENEWABLE MIX

\begin{tabular}{|c|ccc|cc|ccc|}
\hline$\varepsilon$ & $\mathrm{a}_{1}$ & $\mathrm{a}_{2}$ & $\mathrm{a}_{3}$ & $\mathrm{~S}_{\mathrm{Y}}$ & $\mathrm{Q}_{\mathrm{REN}}$ & $\mathrm{Q}_{\mathrm{H}}$ & $\mathrm{Q}_{\mathrm{W}}$ & $\mathrm{Q}_{\mathrm{PV}}$ \\
\hline 0.2 & 818 & 313 & 425 & 1153 & $13 \%$ & $79 \%$ & $14 \%$ & $7 \%$ \\
0.4 & 1844 & 470 & 679 & 1091 & $27 \%$ & $84 \%$ & $10 \%$ & $6 \%$ \\
0.6 & 2780 & 634 & 1027 & 1048 & $41 \%$ & $85 \%$ & $9 \%$ & $6 \%$ \\
0.8 & 3727 & 739 & 1040 & 1022 & $53 \%$ & $87 \%$ & $8 \%$ & $4 \%$ \\
1.0 & 4678 & 828 & 954 & 1007 & $65 \%$ & $89 \%$ & $7 \%$ & $3 \%$ \\
\hline real & 2336 & 3190 & 93 & 1406 & $48 \%$ & $61 \%$ & $39 \%$ & $0.4 \%$ \\
\hline
\end{tabular}

The results presented in Table II show that, by optimizing the renewable generation mix, the residual demand standard deviation is considerably reduced from $1405 \mathrm{MW}$, observed for the real case, to a range between $1007 \mathrm{MW}$ and $1153 \mathrm{MW}$, for the simulated scenarios.

Moreover, as more renewable generation is allowed to instantaneously satisfy the demand, the higher the total renewable share is achieved. This shows that constraint (5) is active and plays an important role in the renewable integration into the Portuguese power system.

It is also concluded that the total renewable share that minimizes the residual demand variability is $65 \%$ without an excess of instantaneous renewable generation.
Simulations were also carried out in order to analyze the impact of different renewable targets in the optimized renewable generation mix.

These simulations considered a balanced scenario between the goals of the residual demand variability minimization and the achievement of a given renewable quota, i.e. $\gamma_{1}=\gamma_{2}=0.5$. These scenarios were obtained by varying $\lambda$ between 0.2 and 0.8 , which corresponds to a total renewable generation share between $20 \%$ and $80 \%$.

As in the base case scenario, the renewable generation is not allowed to exceed the electricity demand in each period $(\varepsilon=1)$.

Table III presents the considered renewable targets in each scenario $(\lambda)$, the optimization results for each renewable technology capacity $\left(a_{1}, a_{2}\right.$ and $\left.a_{3}\right)$, the residual demand standard deviation $\left(\mathrm{s}_{\mathrm{Y}}\right)$, the total renewable quota $\left(\mathrm{Q}_{\mathrm{REN}}\right)$, and the share of each renewable source in the total renewable generation $\left(\mathrm{Q}_{\mathrm{H}}, \mathrm{Q}_{\mathrm{W}}, \mathrm{Q}_{\mathrm{PV}}\right)$.

TABLE III. IMPACT OF THE RENEWABLE GENERATION QUOTA ON THE OPTIMAL RENEWABLE MIX

\begin{tabular}{|c|ccc|cc|ccc|}
\hline$\lambda$ & $\mathrm{a}_{1}$ & $\mathrm{a}_{2}$ & $\mathrm{a}_{3}$ & $\mathrm{~S}_{\mathrm{Y}}$ & $\mathrm{Q}_{\mathrm{REN}}$ & $\mathrm{Q}_{\mathrm{H}}$ & $\mathrm{Q}_{\mathrm{W}}$ & $\mathrm{Q}_{\mathrm{PV}}$ \\
\hline 0.2 & 1302 & 375 & 1099 & 1108 & $21 \%$ & $78 \%$ & $11 \%$ & $12 \%$ \\
0.4 & 2803 & 564 & 1020 & 1048 & $41 \%$ & $86 \%$ & $8 \%$ & $6 \%$ \\
0.6 & 4305 & 753 & 941 & 1012 & $60 \%$ & $89 \%$ & $7 \%$ & $4 \%$ \\
0.8 & 4579 & 1329 & 1681 & 1034 & $69 \%$ & $83 \%$ & $11 \%$ & $6 \%$ \\
\hline real & 2336 & 3190 & 93 & 1406 & $48 \%$ & $61 \%$ & $39 \%$ & $0.4 \%$ \\
\hline
\end{tabular}

From the results presented in Table III it can be seen that the desired renewable quota is achieved very closely in every scenario with the exception of the last because a share of $80 \%$ is only possible if the instantaneous renewable generation exceeds the demand for some periods of time.

The scenario of $\lambda=0.6$ is the one that matches exactly the target renewable share $\left(\mathrm{Q}_{\mathrm{REN}}=60 \%\right)$ because no conflict exists between the two goals of the objective function, as this is very close to the optimal value of renewable share that minimizes the residual demand variability (which is $65 \%$, as presented in Table II).

\section{CONCLUSIONS}

This paper presents a methodology based on a constrained multi-objective optimization that computes the optimal renewable generation mix to be integrated in a power system, taking into account the variability of the residual electricity demand and a given target of renewable share.

The model was applied to the Portuguese power system case study to derive the optimal mix of hydro, wind and PV renewable sources, for a one-month period with a 15 -minute time-step.

The implemented methodology was tested for different scenarios and the achieved results put in evidence an increase 
in the correlation between the optimized renewable generation mix and the electricity demand, resulting in a decreased variability of the residual demand.

Therefore, an improved integration of the renewable generation is achieved both in terms of the short-term system operation and the long-term investments in backup and storage capacity.

These results are achieved with a higher share of hydro and PV generation than in the real case, due to the fact that these technologies are more correlated with the demand than wind. For the base case scenario, with the two goals of the objective function equally balanced, the optimal renewable mix in terms of installed capacity consists of $87.5 \%$ hydro, $7.7 \%$ wind and $4.6 \% \mathrm{PV}$, which compares to $60.6 \%, 38.9 \%$ and $0.4 \%$ of the real case, respectively.

The achieved results highlight that a given renewable target can be achieved in an optimized way in terms of the burden caused for the conventional thermal power plants.

Additional work is under way by the authors in order to include the uncertainty associated with the renewable sources forecasting. Moreover, the model is being expanded to include the levelised costs of each renewable generation technology and the costs associated with the system requirements.

\section{REFERENCES}

[1] Directive 2009/28/EC of the European parliament and of the council of 23 April 2009 on the promotion of the use of energy from renewable sources, Apr. 2009.

[2] 2010 IEA Wind Annual Report, IEA - International Energy Agency, Jul. 2011. [Online]. Available: http://www.ieawind.org/

[3] A. Estanqueiro, J. M. Ferreira de Jesus, J. Ricardo, A. Santos, and J. A. Lopes, "Barriers (and Solutions...) to very high wind penetration in power systems," IEEE Power Engineering Society General Meeting, pp. 1-7, 2007

[4] J. Kaboouris and F. D. Kanellos, "Impacts of large-scale wind penetration on designing and operation of electric power systems," IEEE Trans. Sustainable Energy, vol. 1, pp. 107-114, Jul. 2010

[5] H. Holttinen, A. G. Orths, P. Eriksen, J. Hidalgo, A. Estanqueiro, F. Groome, Y. Coughlan, H. Neumann, B. Lange, F. Hulle, and I. Dudurych, "Currents of change: European experience and perspectives with high wind penetration levels," IEEE Power and Energy Magazine, vol. 9, no. 6, pp. 47-59, Nov./Dec. 2011.

[6] H. Lund, "Large-scale integration of wind power into different energy systems," Energy, vol. 30, pp. 2402-2412, Oct. 2005.

[7] B.C. Ummels, E. Pelgrum, M. Gibescu, and W. L. Kling, "Comparison of integration solutions for wind power in the Netherlands," Renewable Power Generation, IET Research Journals, vol. 3, pp. 279-292, Sep. 2009.
[8] A. Estanqueiro, R. Castro, P. Flores, J. Ricardo, M. Pinto, R Rodrigues, and J. Lopes, "How to prepare a power system for $15 \%$ wind energy penetration: the Portuguese case study," Wind Energy, vol. 11, pp. 75-84, 2008.

[9] P. Moura and A.T. Almeida, "Methodologies and technologies for the integration of renewable resources in Portugal," UNESCO Energy Bulletin, No. 2 (9), pp. 51-60, 2010

[10] S. Faias, J. Sousa, F. Reis, R. Castro, "Assessment and optimization of wind energy integration into the power systems: Application to the Portuguese system," IEEE Trans. on Sustainable Energy, Vol. 3, No. 4, Oct.2012.

[11] H. Holttinen, "The impact of large scale wind power production on the Nordic electricity system," VTT Publications, No. 554, 2004.

[12] H. Holttinen and R. Hirvonen, "Power system requirements for wind power," in Wind Power in Power Systems, T. Ackermann, John Wiley \& Sons, pp. 143-167, 2005.

[13] D. A. Halamay, T. K. A. Brekken, A. Simmons, and S. McArthur, "Reserve requirements impacts of large-scale integration of wind, solar and ocean wave power generation," IEEE Trans. Sustainable Energy, vol. 2, pp. 321-328, Jul. 2011

[14] H. Holttinen, "Hourly Wind Power Variations in the Nordic Countries," Wind Energy, vol. 8, pp. 173-195, 2005.

[15] A. Estanqueiro, "Impact of wind generation fluctuations in the design and operation of power systems," 7th International Workshop on Large Scale Integration of Wind Power and on Transmission Networks for Offshore Wind Farms, Madrid, May 2008.

[16] E. Wiemken, H. G. Beyer, W. Heydenreich, and K. Kiefer, "Power characteristics of PV ensembles: Experiences from the combined power production of 100 grid connected systems distributed over the area of Germany," Sol. Energy, vol. 70, pp. 513-518, 2001.

[17] E. D. Stoutenburg, N. Jenkins, and M. Z. Jacobson, "Power output of co-located offshore wind turbines and wave energy converters in California," Renewable Energy, vol. 35, pp. 2781-2791, 2010.

[18] F. Fusco, G. Nolan, and J. V. Ringwood, "Variability reduction through optimal combination of wind/wave resources-An Irish case study", Energy, vol. 35, pp. 314-325, Jan. 2010.

[19] J. Widén, "Correlations between large-scale solar and wind power in a future scenario for Sweden," IEEE Trans. on Sustainable Energy, vol. 2, pp. 177-184, Apr. 2011.

[20] D. Heide, L. von Bremen, M. Greiner, C. Hoffmann, M. Speckmann, and S. Bofinger, "Seasonal optimal mix of wind and solar power in a future, highly renewable Europe," Renewable Energy, vol. 35, pp. 2483-2489, Nov. 2010.

[21] H. Holttinen, P. Meibom, A. Orths, B. Lange, M. O'Malley, J. O. Tande, A. Estanqueiro, E. Gomez, L. Söder, G. Strbac, J. C. Smith, and F. van Hulle, "Impacts of large amounts of wind power on design and operation of power systems, results of IEA collaboration," Wind Energy, vol. 14, pp. 179-192, 2011.

[22] H. Lund, "Large-scale integration of optimal combinations of PV, wind and wave power into the electricity supply," Renewable Energy, vol. 31, pp. 503-515, 2006.

[23] P. Moura and A.T. Almeida, "Multi-objective optimization of a mixed renewable system with demand-side management," Renewable and Sustainable Energy Reviews, vol. 14, pp. 1461-1468, 2010.

[24] REN, "Electricity real time information". [Online]. Available: www.centrodeinformacao.ren.pt 